\title{
Pengembangan Metode Penilaian Mandiri Kualitas Data Rutin Di Dinas Kesehatan Kota Surakarta
}

\author{
Puguh Ika Listyorini*,Mursid Raharjo **,Farid Agushybana ** \\ *Alumni Magister Ilmu Kesehatan Masyarakat Universitas Diponegoro, **Staf Pengajar Program \\ Magister Ilmu Kesehatan Masyarakat Universitas Diponegoro \\ Email:puguh_ika@yahoo.co.id
}

\section{ABSTRACT}

Data are the basis to make a decision and policy. The quality assessment methods nowadays do not include all indicators of data quality. If the indicators or assessment criteria in the quality assessment methods are more complete, the level of assessment methods of the data will be higher.The purpose of this study is to develop the method of independent assessment of routine data quality in Health Department, Surakarta that previously performed using the data quality assessment of PMKDR and Health Metrick Network (HMN) methods first. The design of this study is research and development $(R \& D)$ that has modified into seven steps, namely formulating potential problems, collecting the data, designing the product, validating the design, fixing the design, testing the product, and fixing the product. The subjects consisted of 19 respondents who are managers of data in Health Department, Surakarta. Data analysis method used is content analysis. The results show that all of pilot phase in data quality assessment can be applied. Quality of data collection is adequate, data accuracy is poor, data consistency exists but inadequate, data actuality is adequate, data periodicity is inadequate, data representation adequate, and data sorting is adequate.It needs a commitment from Surakarta Health Department to develop these methods to assess the quality of data. It can be support the availability of information, decisionmaking and planning of health programs.

Keywords: $\quad P M K D R ; \quad H M N ; \quad R \& D ;$ Surakarta; the Quality of Routine Data

\section{PENDAHULUAN}

Data diartikan sebagai catatan atas kumpulan fakta yang merupakan masukan dari terciptanya sebuah informasi, konsep ini dikaitkan dengan produk informasi yang menggunakan data sebagai masukan, sedangkan informasi didefinisikan sebagai data yang telah diolah sehingga memberikan makna bagi penerima informasi. ${ }^{1,2}$ Data dalam jumlah banyak tidak cukup apabila data tersebut memiliki kualitas rendah. Data dapat diolah dan digunakan sebagai masukan dalam proses pengambilan keputusan atau kebijakan. Keputusan atau kebijakan intervensi program-program kesehatan dibuat dengan dasar data yang belum tentu baik kualitasnya, maka kebenaran intervensi tersebut juga akan 
diragukan kualitas, validitas, dan akurasinya. Data yang tidak akurat jika digunakan sebagai dasar pengambilan keputusan akan menyebabkan keputusan yang diambil kurang valid.

Berdasarkan laporan Pusdatin, kualitas data kesehatan di Indonesia tergolong rendah. ${ }^{3}$ Hasil penilaian terhadap Sistem Informasi Kesehatan (SIK) Indonesia yang dilakukan oleh Health Metrick Network (HMN) yang bekerja sama Pusdatin Kementerian Kesehatan pada tahun 2007, menunjukkan hasil yang tidak adekuat untuk sumber daya (47\%), indikator $(61 \%)$, sumber data $(51 \%)$, kualitas data $(55 \%)$ penggunaan dan diseminasi data (57\%) serta manajemen data $(35 \%)$.

Penilaian kualitas data saat ini dapat dilakukan dengan menggunakan beberapa pendekatan diantaranya metode Routine Data Quality Assessment (RDQA), Data Quality Assessment Framework (DQAF), Health Metrick Network (HMN), dan Penilaian Mandiri Kualitas Data Rutin (PMKDR). Berdasarkan studi literatur yang dilakukan peneliti didapatkan hasil bahwa metode penilaian kualitas data yang ada saat ini hanya menilai beberapa komponen saja. Metode yang sering digunakan untuk menilai data kesehatan adalah metode PMKDR dan HMN.

PMKDR dirancang bagi staf pengolah data program kesehatan ditingkat nasional, provinsi, atau kabupaten atau kota untuk menilai kualitas data rutinsedangkan HMN digunakan untuk melikai Sistem Informasi Kesehatan (SIK) nasional. ${ }^{3,4} \mathrm{PMKDR}$ hanya dapat menilai tiga komponen kualitas data yaitu kelengkapan data, akurasi data dan konsistensi data. Berdasarkan WHO dalam HMN, terdapat enam kriteria penilaian kualitas data yaitu dilihat metode pengumpulan data, aktualitas, periodensitas, konsistensi, keterwakilan dan pemilahan. ${ }^{4}$
Secara umum dapat dikatakan komponen penilaian kualitas data antara lain adalah kelengkapan, akurasi, konsistensi, keunikan, ketepatan waktu, validitas relevansi, komparasi, koherensi, aksesbilitas, metode pengumpulan data, aktualitas, periodesitas, keterwakilan, dan pemilihan. 3,4,5,6. Sedangkan dalam penilaian kualitas data dikenal enam dimensi, antara lain kelengkapan, keunikan, ketepatan waktu, validitas, akurasi, dan konsistensi. ${ }^{5}$ Menurut Bergdahl dalam Handbook on Data Quality Assessment Methods and Tools, indikator kualitas data meliputi enam komponen, antara lain relevansi, akurasi, ketepatan waktu, komparasi, koherensi, serta aksesbilitas dan kejelasan. ${ }^{6}$

Kebutuhan akan data dan informasi yang handal disediakan melalui penyelenggaraan sistem informasi kesehatan, yaitu dengan cara pengumpulan, pengolahan, analisis data serta penyajian informasi. Saat ini metode penilaian kualitas data yang ada masih terfragmentasi serta belum mampu menyediakan informasi yang handal. ${ }^{3}$ Sehubungan dengan hal tersebut maka perlu dikembangkan metode penilaian kualitas data yang mampu menghasilkan data informasi yang akurat, lengkap, tepat waktu, metode pengumpulan data, aktualitas, periodensitas, konsistensi, keterwakilan dan pemilahan.

Berdasarkan permasalahan di atas maka peneliti tertarik untuk melakukan pengembangan metode penilaian mandiri kualitas data rutin di Dinas Kesehatan Kota Surakarta. Sebelum metode penilaian mandiri kualitas data rutin dikembangkan peneliti akan melakukan perbandingan penilaian data dengan menggunakan metode PMKDR dan metode HMN. Hal ini dilakukan sebagai penunjang pengembangan metode penilaian mandiri kualitas data rutin ini. 


\section{METODE PENELITIAN}

Sebagai upaya mencari pembuktian dan solusi dari masalah yang diangkat dalam penelitian ini, peneliti telah menentukan dan merancang desain penelitian dengan desain penelitian research and development (R\&D) atau sering disebut penelitian pengembangan yang telah dimodifikasi. ${ }^{7}$ Penelitian dilaksanakan di Dinas Kesehatan Kota Surakarta.

Subjek penelitian sesuai dengan fokus penelitian, satu orang petugas pengelola data disetiap unit Puskesmas dan dua orang pengelola data di Dinas Kesehatan Kota Surakarta. Total subyek penelitian adalah sebanyak 19 orang dengan rincian 17 orang petugas pengelola data di Puskesmas wilayah kerja Dinas Kesehatan Kota surakarta dan dua orang petugas pengelola data Dinas Kesehatan kota Surakarta. Obyek dari penelitian ini adalah metode PMKDR dan metode HMN yang digunakan untuk menilai kualitas data rutin kesehatan Dinas Kesehatan Kota Surakarta.

Pengumpulan data primer dalam penelitian ini menggunakan kuesioner dan data sekunder melalui telaah dokumen. Setelah pengumpulan data selesai dilaksanakan maka data dianalisis menggunakan metode analisis isi (content analysis) dengan tahapan pengumpulan data, reduksi data, dan penyajian data dan menarik kesimpulan.

\section{HASIL DAN PEMBAHASAN}

\section{Karakteristik Responden}

Responden dalam penelitian ini adalah petugas penggelola data di Puskesmas Wilayah Dinas Kesehatan Kota Surakarta dan Dinas Kesehatan Kota Surakarta. Total responden adalah sebanyak 19 orang dengan rincian 17 orang petugas pengelola data di Puskesmas wilayah kerja Dinas Kesehatan Kota Surakarta dan dua orang petugas pengelola data Dinas Kesehatan Kota Surakarta. Karakteristik responden penelitian ini secara lengkap dapat dilihat pada tabeltabel berikut ini:

Tabel 1. Distribusi Frekuensi Responden Berdasarkan Jenis Kelamin

\begin{tabular}{lrr}
\hline \multicolumn{1}{c}{$\begin{array}{c}\text { Jenis } \\
\text { Kelamin }\end{array}$} & Jumlah & \multicolumn{1}{c}{$\begin{array}{c}\text { Prosentase } \\
(\boldsymbol{\%})\end{array}$} \\
\hline Laki-laki & 5 & 26,3 \\
Perempuan & 14 & 73,7 \\
\hline Total & 19 & 100 \\
\hline
\end{tabular}

Tabel 2. Distribusi Frekuensi Responden Berdasarkan Tingkat Pendidikan

\begin{tabular}{lrr}
\hline $\begin{array}{c}\text { Tingkat } \\
\text { Pendidikan }\end{array}$ & Jumlah & Prosentase (\%) \\
\hline S2 & 1 & 5,3 \\
S1 & 14 & 73,7 \\
D4 & 1 & 5,3 \\
D3 & 3 & 15,8 \\
\hline Total & 19 & 100 \\
\hline
\end{tabular}

Tabel 3 Distribusi Frekuensi Responden Berdasarkan Lama Kerja

\begin{tabular}{lrr}
\hline \multicolumn{1}{c}{$\begin{array}{c}\text { Lama } \\
\text { Kerja }\end{array}$} & Jumlah & \multicolumn{1}{c}{$\begin{array}{c}\text { Prosentase } \\
(\boldsymbol{\%})\end{array}$} \\
\hline$<5$ tahun & 10 & 52,6 \\
$5-10$ tahun & 7 & 36,8 \\
$>10$ tahun & 2 & 10,5 \\
\hline Total & 19 & 100 \\
\hline
\end{tabular}

Penilaian Kualitas Data di Dinas Kesehatan

Kota Surakarta dengan Metode PMKDR

Hasil penilaian kualitas data di Dinas Kesehatan Kota Surakarta dengan menggunakan metode PMKDR dapat dilihat pada gambar berikut:

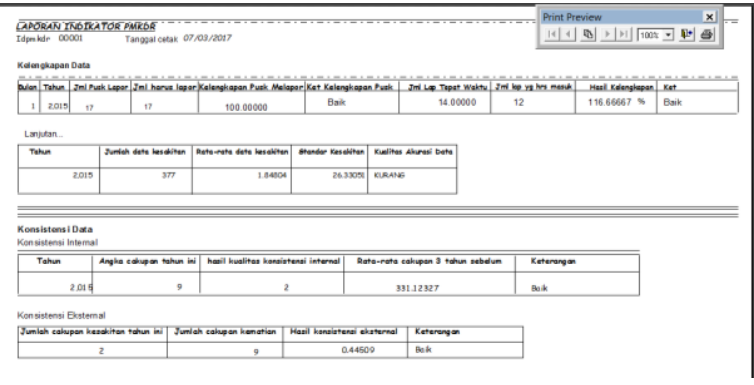

Gambar 1.Tampilan Laporan Hasil 


\section{Perhitungan Indikator PMKDR}

Dalam penilaian kualitas data dengan metode PMKDR ada 4 indikator yang dinilai antara lain:

1. Kelengkapan Data

Prosentase kelengkapan pelaporan Puskesmas menunjukkan angka 100\% tiap bulannya. Definisi dari kelengkapan laporan yaitu jumlah unit atau fasilitas yang melapor dibandingkan dengan jumlah unit atau fasilitas yang seharusnya melapor. ${ }^{3}$ Apabila melihat output di atas maka dapat disimpulkan 17 unit Puskesmas yang seharusnya melapor, semuanya telah melakukan pelaporan setiap bulan selama tahun 2015 .

2. Ketepatan Waktu

Rata-rata ketepatan laporan Puskesmas di Dinas Kesehatan Kota Surakarta adalah 72,6\%. Definisi tepat waktu mengacu pada standar yang sudah berlaku di Indonesia yaitu laporan bulanan dikirim paling lambat tanggal 5 oleh Puskesmas, tanggal 10 oleh kabupaten atau kota, dan tanggal 15 oleh provinsi. $^{3}$ Apabila melihat output di atas dapat diartikan tidak semua Puskesmas di wilayah kerja Dinas Kesehatan Kota Surakarta melaporkan tepat waktu, atau lebih dari tanggal 5 pada bulan setelah pelaporan. ${ }^{3}$

3. Akurasi Data

Perhitungan akurasi data Dinas Kesehatan Kota Surakarta adalah 2,63 $\mathrm{SD}$, artinya data tersebut mempunyai akurasi yang kurang baik. Maka untuk memastikan akurasi data kedua Puskesmas tersebut pihak Dinas Kesehatan Kota Surakarta perlu melakukan verifikasi terhadap wilayah kerja tersebut, karena kemungkinan yang terjadi adalah adanya wabah atau KLB DBD di wilayah tersebut, sehingga laporan terlalu tinggi. ${ }^{3}$
4. Konsistensi Data

Angka cakupan data lebih besar dari ratarata (1/100.000 penduduk). Adanya angka cakupan yang tinggi mengharuskan Dinas Kesehatan Kota Surakarta melakukan verifikasi ke wilayah kerja Puskesmas yang mempunyai angka cakupan tinggi tersebut. Hal yang mungkin terjadi terkait tingginya angka cakupan tersebut adalah adanya penambahan yang sangat mendasar terhadap sumber daya yang ada, baik dari sumber daya tenaga maupun sumber daya peralatan, sehingga cakupan dapat menjadi tinggi atau meningkat tajam. ${ }^{3}$

Penilaian Kualitas Data di Dinas Kesehatan Kota Surakarta dengan Metode HMN

Hasil penilaian kualitas data di Dinas Kesehatan Kota Surakarta dengan menggunakan metode HMN dapat dilihat pada tabel berikut:

Dalam penilaian kualitas data dengan metode HMN ada 7 indikator yang dinilai antara lain: ${ }^{8}$

1. Pengelolaan SIK

Prosentase hasil analisis komponen kebijakan dan organisasi Dinas Kesehatan Kota Surakarta sebesar 93,3\% atau masuk dalam kategori sangat adekuat. Artinya dalam pengelolaan SIK Dinas Kesehatan Kota Surakarta terdapat peraturan dan prosedur terkait SIK, dokumen Renstra tentang SIK, dan sumberdaya SIK yang memadai. ${ }^{4}$

2. Sumber Daya SIK

Besar komponen sumber daya Dinas Kesehatan Kota Surakarta sebesar 74,2\% atau adekuat. Hal ini dapat diartikan bahwa terdapat SDM SIK memadai, ada pendampingan petugas SIK, ada angaran khusus untuk SIK, serta terdapat perangkat SIK yang memadai. ${ }^{4}$

5. Indikator SIK 
Prosentase hasil analisis komponen indikator Dinas Kesehatan Kota Surakarta sebesar $84,7 \%$ atau sangat adekuat. Hal ini menandakan bahwa penentuan indikator sudah mencakup semua kategori, dipilih sesuai dengan kriteria kegunaan, ditentukan oleh kepala daerah yang mengacu pada indikator sebelumnya, dan pelaporan dilakukan secara teratur dan lengkap. ${ }^{4}$

\section{Sumber Daya Data SIK}

Prosentase hasil analisis komponen indikator Dinas Kesehatan Kota Surakarta sebesar 68,5\% atau adekuat. Artinya bahwa untuk mendapatkan data kesehatan di Dinas Kesehatan Kota Surakarta telah mempunyai kapasitas melakukan survei, memproses data, menganalisis data yang ada, melakukan pemilahan data berdasarkan kriteriakriteria tertentu, yang tentunya dilakukan oleh sumber daya yang terampil dan memadai untuk mengelola data yang ada. $^{4}$

7. Manajemen Data SIK

Prosentase hasil analisis komponen indikator Dinas Kesehatan Kota Surakarta sebesar $61,8 \%$ atau masuk dalan kategori adekuat. Hal ini menunjukkan bahwa pengelolaan manajemen data SIK di Dinas Kesehatan Kota Surakarta mempunyai prosedur tertulis untuk pengelolaan data., bank data, serta terdapat kode identifikasi unil untuk setiap unit administrasi, agar database pada setiap unit dapat bergabung atau menyatu. ${ }^{4}$

3. Produk Informasi SIK

Secara garis besar komponen produk informasi Dinas Kesehatan Kota Surakarta sebesar $85,5 \%$ atau ada tetapi tidak adekuat. Artinya dalam pengelolaan indikator status kesehatan, sistem kesehatan, dan faktor resiko Dinas Kesehatan Kota Surakarta menggunakan metode pengumpulan data yang tepat, data yang dikumpulkan juga merupakan data aktual, melakukan pengumpulan atau pengukuran data secara periodik dan teratur, tidak ada perbedaan data yang signifikan, survei dilakukan pada lebih dari $90 \%$ populasi, dan juga telah melakukan pemilahan data berdasarkan karakteristik demografi, status sosial ekonomi dan wilayah ${ }^{4}$.

4. Diseminasi dan Penggunaan SIK

Secara garis besar komponen penyebaran dan penggunaan Dinas Kesehatan Kota Surakarta sebesar $88,4 \%$ atau sangat adekuat. Hal ini menunjukkan bahwa dari segi diseminasi informasi, pembuat kebijakan di Dinas Kesehatan Kota Surakarta membutuhkan informasi yang lengkap, tepat waktu, akurat, relevan, valid, informasi yang berupa grafik, dan informasi yang berupa peta. Sedangkan dari segi pengguna informasi, laporan SIK sudah didistribusikan secara teratur ke semua pihak, dan informasi tersebut digunakan untuk perencanaan program kesehatan oleh kepala Dinas Kesehatan Kota Surakarta ${ }^{4}$.

Tabel 4. Kualitas Data Dinas Kesehatan Kota Surakarta Indikator HMN

\begin{tabular}{|c|c|c|c|}
\hline No & Kategori & Persentase & Keterangan \\
\hline 1 & Pengelolaan & $93,3 \%$ & $\begin{array}{l}\text { Sangat } \\
\text { adekuat }\end{array}$ \\
\hline 2 & Sumber Daya & $74,2 \%$ & Adekuat \\
\hline 3 & Indikator & $84,7 \%$ & $\begin{array}{l}\text { Sangat } \\
\text { adekuat }\end{array}$ \\
\hline 4 & Sumber Data & $68,6 \%$ & Adekuat \\
\hline 5 & $\begin{array}{l}\text { Manajemen } \\
\text { Data }\end{array}$ & $61,7 \%$ & Adekuat \\
\hline 6 & $\begin{array}{l}\text { Produk } \\
\text { Informasi }\end{array}$ & $85,5 \%$ & $\begin{array}{l}\text { Sangat } \\
\text { adekuat }\end{array}$ \\
\hline 7 & $\begin{array}{l}\text { Diseminasi \& } \\
\text { Penggunaan } \\
\text { Informasi }\end{array}$ & $88,3 \%$ & $\begin{array}{l}\text { Sangat } \\
\text { adekuat }\end{array}$ \\
\hline & Keseluruhan & $79,7 \%$ & Adekuat \\
\hline
\end{tabular}




\section{Perbandingan Metode PMKDR dan HMN}

Setelah dilakukan penilaian kualitas data rutin dengan mengunakan metode PMKDR dan HMN, maka dapat diperbandingkan antara dua metode tersebut antara lain dalam tabel berikut :

Tabel 5. Perbandingan PMKDR dan HMN

\begin{tabular}{|c|c|c|}
\hline Pembeda & Metode PMKDR & Metode HMN \\
\hline Penjelasan & $\begin{array}{l}\text { Penilaian Mandiri } \\
\text { Kualitas Data } \\
\text { Rutin (PMKDR) } \\
\text { diterbitkan oleh } \\
\text { Kementerian } \\
\text { Kesehatan } \\
\text { Republik } \\
\text { Indonesia, berupa } \\
\text { seperangkat } \\
\text { metode untuk } \\
\text { menilai kualitas } \\
\text { data rutin secara } \\
\text { mandiri yang } \\
\text { dilaksanakan } \\
\text { secara reguler. }\end{array}$ & $\begin{array}{l}\text { Health Metrics Network } \\
\text { (HMN) diterbitkan oleh } \\
\text { WHO, merupakan } \\
\text { assessment tool yang } \\
\text { digunakan untuk menilai } \\
\text { atau mengevaluasi sistem } \\
\text { informasi kesehatan di } \\
\text { suatu daerah atau negara. }\end{array}$ \\
\hline $\begin{array}{l}\text { Yang } \\
\text { dinilai }\end{array}$ & $\begin{array}{l}\text { Menilai kualitas } \\
\text { data rutin. }\end{array}$ & $\begin{array}{l}\text { Menilai sistem informasi } \\
\text { kesehatan daerah atau } \\
\text { pusat, komponen yang } \\
\text { dinilai adalah } \\
\text { - } \quad \text { Sumber daya SIK } \\
\text { - } \quad \text { Indikator } \\
\text { - } \quad \text { Sumber daya data } \\
\text { - } \quad \text { Manajemen data } \\
\text { - } \quad \text { Produk informasi } \\
\text { - } \quad \text { Penyebaran dan } \\
\quad \text { penggunaan } \\
\text { informasi }\end{array}$ \\
\hline $\begin{array}{l}\text { Indikator } \\
\text { dan } \\
\text { Kriteria } \\
\text { Penilaian } \\
\text { Kualitas } \\
\text { Data }\end{array}$ & $\begin{array}{l}\text { Kelengkapan data } \\
\text { Akurasi Data } \\
\text { Konsistensi } \\
\text { Internal } \\
\text { Konsistensi } \\
\text { Eksternal }\end{array}$ & $\begin{array}{l}\text { Metode Pengumpulan } \\
\text { Data } \\
\text { Aktualitas } \\
\text { Periodesitas } \\
\text { Konsistensi } \\
\text { Pemilahan } \\
\text { Keterwakilan }\end{array}$ \\
\hline $\begin{array}{l}\text { Data yang } \\
\text { dianalisis }\end{array}$ &  & $\begin{array}{l}\text { Bersifat kategorik, berupa } \\
\text { data primer dari hasil } \\
\text { survei ke Puskesmas. }\end{array}$ \\
\hline
\end{tabular}

Hasil Pengembangan Metode Penilaian

\section{Mandiri Kualitas Data Rutin}

Berdasarkan hasil analisis kelemahan serta kelebihan metode PMKDR dan HMN, bahwa antara metode HMN dan PMKDR mempunyai sisi keunggulan dan kelemahan masing-masing, maka peneliti melakukan pengembangan perangkat metode penilaian kualitas data dengan mengabungkan indikator kualitas data berdasarkan metode PMKDR dan indikator kualitas data berdasarkan metode HMN. Hasil pengembangan perangkat metode penilaian kualitas data setelah dilakukan pengembangan digunakan untuk menilai data rutin cakupan demam berdarah dengue. Tahap kegiatan pengembangan dalam penelitian ini berdasarkan tahap kegiatan penelitian R\&D manurut Sugiyono, yaitu: ${ }^{7}$

1. Merumuskan potensi masalah

2. Pengumpulan data

3. Desain metode

4. Penilaian metode

5. Perbaikan metode

6. Uji coba metode

7. Perbaikan

Output penilaian kualitas data rutin ini menunjukkan hasil penilaian kualitas data berdasarkan tujuh indikator dari hasil modifikasi dan penggabungan metode PMKDR dan HMN. Tujuh indikator tersebut antara lain pengumpulan data, akurasi, konsistensi, aktualitas, periodesitas, data, serta pemilahan. Adapun output laporan dari hasil aplikasi pengembangan kualitas data yang dikembangkan dapat dilihat dalam gambar di bawah ini : 


\begin{tabular}{|c|c|c|c|c|}
\hline \multicolumn{2}{|c|}{$\begin{array}{ll}\text { Periode Bulan } & 12 \\
\text { Tanggal cetak } & 06 / 03 / 2017\end{array}$} & \multicolumn{3}{|c|}{$\begin{array}{l}\text { RUaATrAas DATA RUTIN } \\
\text { DTNAS KESERATAN ROTA SURARARTA }\end{array}$} \\
\hline No & Indikator & $\mathrm{N}_{11}$ & & Reterangan \\
\hline 1 & Pengumpulan Data & 94.36275 & $:$ & Sangat adekvat \\
\hline 2 & Akurasi Data & 2.630051 & & RURAMG \\
\hline${ }^{3}$ & Konsisteng1 Data & 43.46000 & + & Ada tap1 t1dak adekuat \\
\hline 4 & Aktualitas Data & 88.2353 & 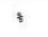 & Sangat adekruat \\
\hline & Periodesitas Data & 90.1961 & 1 & Sangat adekuat \\
\hline 6 & Reterwakilan Data & 90.1961 & : & Sangat adekvat \\
\hline & Peni1ahan Data & 99.0196 & 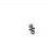 & Sangat adekuat \\
\hline
\end{tabular}

Gambar 2. Output Penilaian Kualitas Data Rutin dari Hasil Pengembangan Metode

Dalam tahap uji coba dari hasil pengembangan metode penilaian kualitas data yang telah dikembangkan pada dasarnya berhasil, atau dapat digunakan. Hasil penilain kualitas data dengan metode yang dikembangkan adalah kualitas pengumpulan data yang sangat adekuat (94,3\%), kualitas akurasi data kurang baik $(\mathrm{SD}=2,63)$, kualitas konsistensi data ada tetapi tidak adekuat (43,5\%), kualitas aktualitas data sangat adekuat $(88,2 \%)$, kualitas periodisitas data sangat adekuat $(90,2 \%)$, kualitas keterwakilan data sangat adekuat (90,2\%), dan pemilahan data sangat adekuat $(99,02 \%)$.

\section{KESIMPULAN}

Kelengkapan laporan tiap bulan dan tiap Puskesmas $100 \%$ lengkap, ketepatan waktu melapor tiap bulan adalah $81,4 \%$ dan tiap Puskesmas $72,6 \%$, nilai akurasi data lebih dari 2SD (kurang baik), konsistensi internal kurang baik, dan angka konsistensi eksternal baik. Hasil penilaian komponen SIK di Dinas Kesehatan Kota Surakarta untuk penggelolaan SIK 93,3\%, sumber daya $74,2 \%$, indikator $84,7 \%$, sumber data $68,6 \%$, produk informasi $85,5 \%$, dan diseminasi dan penggunaan informasi $88,3 \%$. Secara keseluruhan komponen yang dinilai menunjukkan hasil 79,7\%. Antara metode HMN dan PMKDR mempunyai sisi keunggulan dan kelemahan masing-masing, sehingga tidak dapat dikatakan metode PMKDR lebih unggul dibandingkan dengan metode HMN atau sebaliknya.Telah dikembangkan metode penilaian kualitas data dengan mengabungkan indikator kualitas data menurut PMKDR dan HMN dangan metode penelitian RND yang dimodifikasi dengan tujuh indikator yaitu kualitas pengumpulan data, akurasi data, konsistensi data, aktualitas data, periodesitas data, keterwakilan data, serta pemilahan data

\section{DAFTAR PUSTAKA}

1. Vardiansyah D. Filsafat Ilmu Komunikasi: Suatu Pengantar, Indeks, . Jakarta; 2008.

2. Al-Hakim L. Information Quality Management: Theory and Applications. Hershey: Idea Group Publishing.; 2007.

3. Kementrian Kesehatan Republik Indonesia. Penilaian Mandiri Kualitas Data Rutin ( PMKDR ) Sistem Informasi Kesehatan. In: Jakarta: Kementerian Kesehatan RI; 2013.

4. World Health Organization. Assessing the National Health Information System (An Assessment Tool Version 4.00). (World Health Organization, ed.).; 2008.

5. The Premier Organisation For Data Professionals in the UK. The Six Primary Dimensions For Data Quality Assassment (Defining Data Quality Dimension). In: United Kingdom: Dama United Kingdom; 2013. http://www.enterprisemanagement360. com/wpcontent/files_mf/1407250286DAMAU KDQDimensionsWhitePaperR37.pdf. 
6. Bergdahl M, Ehling M, Elvers E, Földesi E. Handbook on Data Quality Assessment Methods and Tools. Wiesbaden; 2007. http://unstats.un.org/unsd/dnss/docsnqaf/Eurostat-HANDBOOK ON DATA QUALITY ASSESSMENT METHODS AND TOOLS I.pdf.

7. Sugiyono. Metode Penelitian Kuantitatif Kualitatif Dan $R \& D$. Bandung: Alvabeta; 2015.

8. Kementrian Kesehatan Republik Indonesia. Peraturan Pemerintah Republik Indonesia Nomor 46 Tahun 2014 Tentang SIstem Informasi Kesehatan. Jakarta; 2014. 